\title{
Mapping for Quantitative Trait Loci and Major Genes Associated with Fresh-cut Browning in Apple
}

\author{
Rui Sun ${ }^{1}$ and Hui Li ${ }^{1}$ \\ Institute for Horticultural Plants, China Agricultural University, 100193, \\ Beijing, China
}

Qiong Zhang
Wuhan Botanical Garden, Chinese Academy of Sciences, 430074, Wuhan,
China

Dongmei Chen, Fengqiu Yang, and Yongbo Zhao

Changli Institute of Pomology, Hebei Academy of Agriculture and Forestry

Sciences, 066600, Changli, China

Yi Wang
Institute for Horticultural Plants, China Agricultural University, 100193,
Beijing, China

Yuepeng Han

Wuhan Botanical Garden, Chinese Academy of Sciences, 430074, Wuhan, China

Xinzhong Zhang and Zhenhai Han'2
Institute for Horticultural Plants, China Agricultural University, 100193,
Beijing, China

Additional index words. flesh browning, inheritance, Malus domestica Borkh., SSR

\begin{abstract}
Flesh browning is an important negative trait for quality preservation of freshcut fruits. To obtain a better understanding of the inheritance and genetic control of flesh browning in apple, the phenotype of a hybrid population derived from 'Jonathan' $\times$ 'Golden Delicious' was studied for 2 successive years. The inheritance of the flesh browning trait was analyzed by the frequency distribution of the phenotypes. Flesh browning-associated major genes were then mapped by screening genome-wide simple sequence repeat (SSR) markers. Flesh browning is inherited quantitatively and showed a clear bimodal frequency distribution, indicating that the segregation of major genes is involved in the variation. The segregation ratio of light and heavy browning was 7:1 in 2010, 2011, and $2010+2011$, suggesting that the inheritance of the trait in apple involves three segregated loci of major genes. The heritability of the major gene effect was $72.14 \%$ and $\mathbf{7 2 . 7 6} \%$ in 2010 and 2011 , respectively. SSR markers were screened from 600 pairs of SSR primers located on 17 apple linkage groups (LGs). The three major genes were mapped on LG10, 15, and 17 on the apple genome, respectively, by linkage analysis of flesh browning phenotypes and the genotypes of SSR markers. Two quantitative trait loci (QTLs) for flesh browning were mapped on LG15 of 'Jonathan' and LG17 of 'Golden Delicious', respectively, which are the same linkage groups that two major genes mapped on.
\end{abstract}

In the last decade, the consumer's requirement for convenience fruits and vegetables such as fresh-cut apples has increasingly expanded. However, the shelf life and quality

Received for publication 19 Aug. 2013. Accepted for publication 5 Nov. 2013.

This work was funded partially by the National Special Funds for Scientific Research on Public Causes (Agriculture) (200903044), National Basic Research Program of China (grant 2011CB100602), and the National High-Tech R\&D Program of China (2011AA001204).

${ }^{1}$ Authors with equal contribution to this work.

${ }^{2}$ To whom reprint requests should be addressed; e-mail rschan@cau.edu.cn. preservation of fresh-cut fruits are challenging. One limiting factor is post-harvest flesh browning in many fruits, including apple.

The browning of fresh-cut apple mainly results from enzymatic browning of phenolic compounds, catalyzed by polyphenol oxidase (PPO) in the flesh tissue (Gil et al., 1998). Therefore, flesh browning is affected by many factors related to polyphenol oxidation. As a substrate of enzymatic browning, the content of phenolic compounds directly affects flesh browning. The main phenolic compounds causing apple browning are chlorogenic acid and flavan-3-alcohols (Amiot et al., 1992). Once oxidized, phenolic compounds turn into quinone and polymerize to produce brown, red, and black pigments (Martínez and Whitaker, 1995). The activity of relevant enzymes also affects the rate of flesh browning. PPO activity is directly related to the rate of flesh browning in 'Classic Delicious', 'Rhode Island Greening', 'McIntosh', and other apple cultivars (Coseteng and Lee, 1987). In addition to polyphenols and PPO, ascorbic acid, like many other antioxidants in the cells, inhibits enzymatic browning, and its content is an important factor influencing apple browning (Nicolas et al., 1994).

Several techniques are currently used to control flesh browning, e.g., thermal treatment, low $\mathrm{O}_{2}$-high $\mathrm{CO}_{2}$ environment, and immersion with color-protection agents. Among these techniques, heat treatment can inactivate the PPO, thus reducing flesh browning. However, heat treatment also changes the structure of flesh tissue and damages some nutrients (Lamikanra, 2002). Low $\mathrm{O}_{2}$ and high $\mathrm{CO}_{2}$ environments can reduce the browning of fresh-cut apple slices (Gunes et al., 2001); a high $\mathrm{CO}_{2}$ level has a negative impact on the physiological function of flesh tissue (Gorny et al., 2002). As color-protection agents, ascorbic acid and its derivatives as well as $\mathrm{N}$-acetylcysteine, 4-hexylresorcinol, and calcium propionate can inhibit enzymatic browning in apple (Buta et al., 1999; DorantesAlvarez et al., 1998). However, chemical treatment increases the cost and may have potential food safety problems by inappropriate use or excessive residual of these agents. Therefore, selection of cultivars resistant to flesh browning is the best solution to reduce flesh browning and to maintain maximum fruit quality during fresh-cut apple processing.

Post-harvest flesh browning in apples varies significantly among cultivars. During fresh-cut apple processing, 'Golden Delicious', 'Delicious', and 'Jonagold' had a low rate of flesh browning, and 'McIntosh' and 'Braeburn' had a high rate of flesh browning (Kim et al., 1993; Luo and Barbosa-Cánovas, 1997). The rate of browning varies because of different levels of phenolic compounds in different cultivars of apple. Total content of phenolic compounds in 'Golden Delicious' were lower than in 'Fuji' and 'Starkrimson' (Nie and Sun, 2005).

The content and composition of phenolic compounds differ in 10 apple processing cultivars; four cider apple cultivars, Marie Menard, Frequin Rouge, Kermerrien, and Douce Coetlignel, and six juice cultivars, Judeline, Judaine, Judestar, Juliana, Jurella, and Granny Smith which were grown in the same orchard at Xiaojinkou, Shandong, China; whereas total phenolic compounds content in cider cultivars is significantly higher than that in juice cultivars (Song et al., 2007). In addition, the PPO activity varies with substrate, leading to changes in the rate of flesh browning in different apple cultivars. The PPO activity in 'Starkrimson' is higher than other cultivars when using chlorogenic acid as a substrate but is higher in 'Orin' when catechin is used as a substrate (Nie et al., 2004).

The flesh browning trait is thought to be inherited quantitatively, and is controlled by 
polygenes. Flesh browning-associated QTLs have been mapped in a hybrid population derived from 'Telamon' $\times$ 'Braeburn' by using the data collected in 2005, and two relevant major QTLs were located on LG3 and 17 of the apple genome (Kenis et al., 2008). The two major QTLs accounted for $66.2 \%$ and $76.9 \%$ of the total variation in this segregating population, respectively. However, the authors identified no QTLs in 2004, indicating that the results of QTL mapping were completely different in these 2 years. On the other hand, some QTLs identified from different hybrid population may differ apparently (Kenis et al., 2008; Kumar et al., 2012; Liebhard et al., 2003). QTLs with robustness between hybrid populations and consistency between years are more satisfactory for potential use in markerassisted breeding.

Previously, the rate of flesh browning was determined to be higher in 'Jonathan' and lower in 'Golden Delicious' (Kim et al., 1993). In the present study, to further understand the inheritance of the apple flesh browning trait, phenotypes of seedlings in a segregating population from 'Jonathan' $\times$ 'Golden Delicious' were studied in 2010 and 2011. The data were analyzed by the frequency distribution of phenotypes and assisted by SSR markerbased major gene mapping and QTL mapping for flesh browning.

\section{Materials and Methods}

Plant material. The segregating population used in this study consisted of 1733 hybrid seedlings of 'Jonathan' $x$ 'Golden Delicious' from the Changli Institute of Pomology, Hebei Academy of Agriculture and Forestry Sciences. The hybridization was made in 2002 and the seedlings on their own roots were transplanted at a density of $0.5 \mathrm{~m} \times$ $2 \mathrm{~m}$ in 2003. The seedlings were maintained under conventional management and pest control. Ripened apple fruit, determined by the seeds becoming dark brown in color, was harvested from different positions of the canopy on each seedling for flesh browning scoring in 2010 and 2011.

Phenotyping for flesh browning. The experimental variation during phenotyping was estimated using analysis of variance (ANOVA) with 30 apples (with three replicates totally and 10 apples for each replicate) from each seedling fruiting in both years. However, because of alternate bearing, 429 seedlings in 2010 and 108 seedlings in 2011 set enough fruit for phenotyping, and 31 seedlings set fruit in both 2010 and 2011. Therefore, 30 seedlings, excluding one producing less than 30 apples, were used for ANOVA.

Fully ripened fruit were randomly collected from each seedling, and the flesh browning score was measured using an HP-200 colorimeter (Hanpu, Shanghai) following the method described by Wang et al. (2004). The apple was first cut into two equal halves along the longitudinal axis of the pedicel and calyx. The flesh surface of each half was exposed to the air for $40 \mathrm{~min}$ at room temperature to let them brown base on the preliminary experiments. Each half fruit was then cut longitudinally into two equal pieces along the same axis; the newly cut surface is perpendicular to the previous one. The CIE coordinates, $L^{*}$ (lightness), $a^{*}$ (red-green), and $b^{*}$ (yellowblue), of fresh-cut surface and browning surface were measured for each piece of fruit using the HP-200 colorimeter. The flesh browning score was calculated using the formula $\Delta \mathrm{E}^{*} \mathrm{a}^{*} \mathrm{~b}^{*}=\left[\left(\Delta \mathrm{L}^{*}\right)^{2}+\left(\Delta \mathrm{a}^{*}\right)^{2}+\right.$ $\left.\left(\Delta \mathrm{b}^{*}\right)^{2}\right]^{0.5}$ (Choi et al., 2002).

Analysis of inheritance. The inheritance of flesh browning was analyzed using Microsoft Excel 2003 (Microsoft Inc., Redmond, WA) by the frequency distribution of phenotype values collected in 2010 and 2011 as well as $2010+2011$. The value of intersection point (if there was) of the two Gaussian curves in the distribution diagram was determined as the cutoff point for light and heavy browning. The individuals in which flesh browning score was less than the cutoff point were categorized as light browning and otherwise the individuals with browning scores larger than the cutoff value were treated as heavy browning. The segregation ratio between light and heavy browning was examined by a $\chi^{2}$ test. Heritability of flesh browning was estimated using variance analysis in the segregating population following the method of Sun et al. (2012). The parental phenotype values of flesh browning were scored with 30 fruit from each maternal parent 'Jonathan' and paternal cultivar Golden Delicious. The environmental effect variance (Se) was presented as the mean value of the parental variances. Then, the mean values $(\mathrm{Sm})$ of the internal variances of the two independent distributions were calculated. Theoretically, the average values $(\mathrm{Sm})$ included polygene effect variance (Si) and environmental effect variance (Se) only. Thus, the equation was $\mathrm{Si}=\mathrm{Sm}-\mathrm{Se}$. The major gene effect variance (Sa) was calculated using average phenotype values of two distributions with low and high flesh browning score. The interaction between the environment and genes was ignored because it is impossible to be estimated by this experimental design. Total population variance was $\mathrm{S}=\mathrm{Sa}+\mathrm{Si}+\mathrm{Se}$. Finally, the heritability of relevant major gene effect $(\mathrm{Sa} / \mathrm{S})$ and polygene effect $(\mathrm{Si} / \mathrm{S})$ was calculated.

Construction of the segregating population. According to the frequency distribution diagram of phenotypic values of flesh browning in 2010, randomly selected 100 seedlings with light-browning phenotype and all of the 50 seedlings with heavy-browning phenotype were used to construct the segregating population for linkage analysis of relevant major genes. Young leaves were sampled from each seedling of the segregating population in 2010. Total genomic DNA was extracted from young leaves using the modified CTAB method (Maguire et al., 1994). DNA quality was checked using $1 \%$ agarose electrophoresis gels. The concentration and purity of the DNA were determined using a ultraviolet spectrophotometer. The final DNA concentration was adjusted to $100 \mathrm{ng} \cdot \mu \mathrm{L}^{-1}$.
SSR genotyping. Six hundred pairs of primers were selected from previously published SSRs and expressed sequence tag (EST)-SSRs based on the apple EST library (Gianfranceschi et al., 1998; Guilford et al., 1997; Hokanson et al., 1998; Liebhard et al., 2002; Silfverberg-Dilworth et al., 2006; Zhang et al., 2012). Total genomic DNA of the two parents and eight randomly selected offspring seedlings were used as templates for screening primer polymorphisms.

SSR genotyping was performed with selected polymorphic primers in the segregating population comprising 150 seedlings. The polymerase chain reaction (PCR) amplification reaction $(20 \mu \mathrm{L})$ contained $20 \mathrm{ng}$ template DNA, $2.0 \mu \mathrm{L} 10 \times$ buffer, $200 \mu \mathrm{M}$ each dNTP, $0.4 \mu \mathrm{M}$ forward and reverse primers, and $0.4 \mathrm{U}$ Taq DNA polymerase. The amplification program was: denaturation at $94{ }^{\circ} \mathrm{C}$ for $4 \mathrm{~min}$; 32 cycles of denaturation at $94^{\circ} \mathrm{C}$ for $1 \mathrm{~min}$, annealing at $55^{\circ} \mathrm{C}$ for $40 \mathrm{~s}$, and extension at $72{ }^{\circ} \mathrm{C}$ for $1 \mathrm{~min}$; final extension at $72{ }^{\circ} \mathrm{C}$ for $5 \mathrm{~min}$; and holding at $4{ }^{\circ} \mathrm{C}$. The PCR products were separated using $8 \%$ polyacrylamide gel electrophoresis and then visualized by silver staining. The DNA ladder was "puc18/Msp I" (RealTimer BioTech Co., Beijing, China).

Mapping for major genes and genotypes of the parents. In the segregating population, seedlings with light-browning phenotype were selected randomly and will thus have one or more gene alleles for light browning. In contrast, the seedlings with heavybrowning genotype will lack all the three dominant loci. So the markers that are present in most seedlings of light browning but are completely or almost absent in the seedlings with heavy-browning phenotype were selected. The polymorphic markers present at low frequency in the seedlings with heavy-browning phenotype were treated as recombinant between the targeted gene and linked markers.

Linkage between related genotypes of SSR markers and flesh browning phenotypes of all 50 seedlings with heavy-browning phenotype was analyzed using Mapmaker/ EXP3.0 software (Lincoln et al., 1992). Map distances in centi Morgans (cM) were calculated from recombination frequencies by using Kosambi's mapping function, and the maximum distance and the likelihood of odd (LOD) threshold were set $37.2 \mathrm{cM}$ and 3.0, respectively. The linkage mapping of the major gene loci involved in flesh browning was generated by MapDraw2.0 (Liu and Meng, 2003).

The parental genotypes were estimated according to the segregation ratio of the markers in the 100 seedlings with lightbrowning phenotype and the appearance of them in samples of the parents.

QTL analysis for flesh browning. The QTL analysis was carried on using the two parental maps constructed with 242 seedlings randomly selected from the same hybrid population (Zhang et al., 2012). The analysis software was MapQTL 6.0 (Van Ooijen et al., 2009). Two different models, interval 
mapping and Kruskal-Wallis analysis, were used for QTL detection. For interval mapping, the genome-wide significant threshold according to the 1000 permutation tests was an LOD score of 2.8, but the chromosomal threshold was also considered to declare QTL locus (Xu et al., 2012). In Kruskal-Wallis analysis, QTL-associated markers were obtained at the $P$ value of 0.01 .

\section{Results}

Sample size for reliable phenotyping. The ANOVA of phenotypic values showed a highly significant variation in flesh browning score among apple seedlings $\left(\mathrm{F}=4.94, \mathrm{~F}_{0.01}=\right.$ $2.42)$, but not between years $\left(\mathrm{F}=3.59, \mathrm{~F}_{0.05}=\right.$ 4.18) and replicates $\left(\mathrm{F}=1.03, \mathrm{~F}_{0.05}=3.33\right)$. This indicated that the flesh browning trait segregated significantly in this hybrid population but was invariable between sampling years. Because the variation between replicates with 10 apples was not significant, 10 apples would be sufficient sample size for reliable phenotyping.

Analysis of frequency distribution. Parental phenotypic value of flesh browning was 5.68 for 'Jonathan' and 4.41 for 'Golden Delicious', but flesh browning segregated as 0.84 to 11.05 and 0.95 to 11.73 in 2010 and 2011, respectively. As shown in Figure 1, the frequency distribution diagrams of flesh browning were typically bimodal in both 2010 and 2011 as well as in the combined data of $2010+2011$, indicating not only robustness over years, but also the involvement of major genes in the inheritance of this trait.

As listed in Table 1, the cutoff criteria of light and heavy browning were 5.70, 6.88, and 5.77 in 2010, 2011, and $2010+2011$, respectively. The segregation ratios between light- and heavy-browning seedlings were $379: 50,91: 17$, and 435:71 in 2010, 2011, and $2010+2011$, respectively. Results of a $\chi^{2}$ test indicated that each of these ratios was significantly different from 3:1 and 15:1 but not different from 7:1. The segregation of one major gene locus (e.g., Aa×aa) may result in half of offspring individuals with a recessive phenotype and the ratio of dominant vs. recessive phenotypes will be $1: 1$. The phenotypic segregation ratio of $7: 1$ is caused by the segregation of two or three major gene loci, e.g., AaBb $\times$ Aabb or AaBbcc $\times a a b b C c$. The results therefore indicated that the variation in flesh browning was caused by the segregation of two or three independently segregating major genes, three in the case of different single parental loci (e.g., AaBbcc $\times a a b b C c)$ and two in case one locus was segregating in both parents (e.g., AaBb $\times$ Aabb) and that light browning is dominant against heavy browning.

Heritability estimates. The heritability estimates of flesh browning in the hybrid population of 'Jonathan' $\times$ 'Golden Delicious' are listed in Table 2. The heritability of major gene effect was $72.14 \%, 72.76 \%$, and $67.72 \%$ in 2010, 2011, and 2010 + 2011, respectively, whereas heritability of polygene effect was $13.23 \%, 15.32 \%$, and $18.77 \%$ in 2010,2011 , and $2010+2011$, respectively.

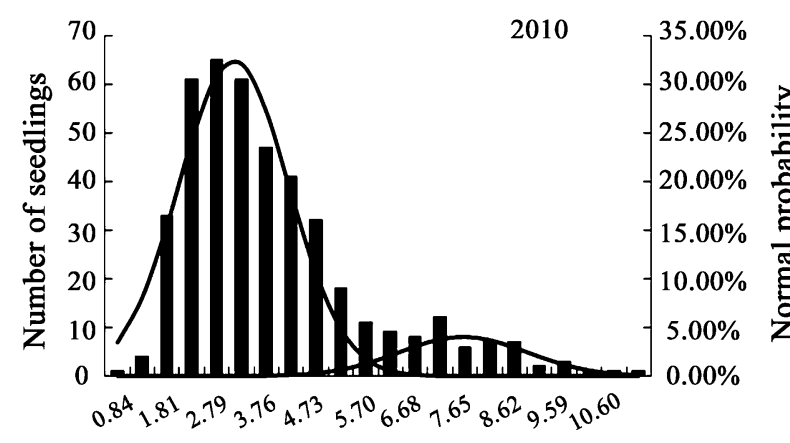

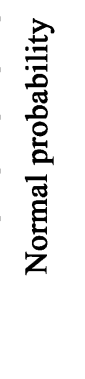

Flesh browning

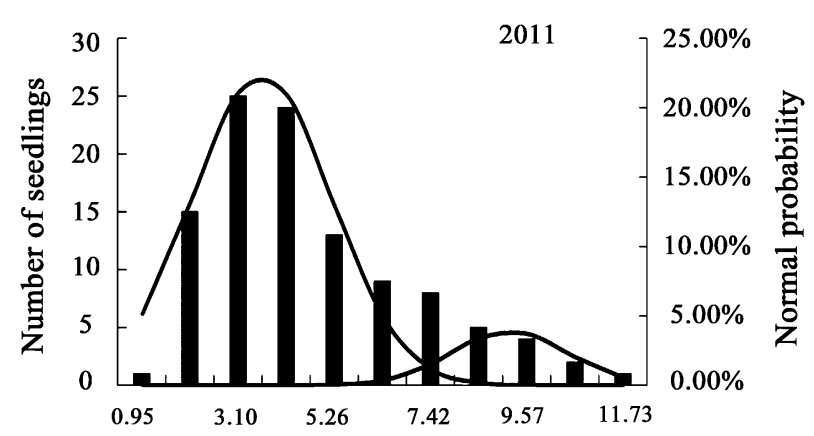

Flesh browning

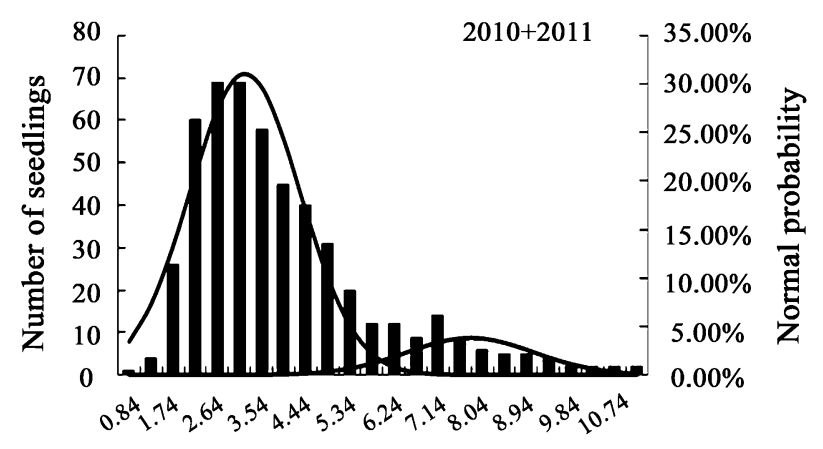

Flesh browning

Fig. 1. Frequency distribution diagram of flesh browning in a hybrid population of 'Jonathan' $\times$ 'Golden Delicious'. The three frequency distributions were generated from data in 2010, 2011, and $2010+$ 2011, respectively.

Table 1. The cutoff point, segregation ratio, and $\chi^{2}$ test of light and high heavy browning in the hybrid population of 'Jonathan' $\times$ 'Golden Delicious'.

\begin{tabular}{lcccccc}
\hline Yr & Cutoff point & Observed segregation ratio & Expected ratio & $\chi^{2}$ & $\chi^{2} 0.05$ & $\chi^{2} 0.01$ \\
\hline 2010 & 5.70 & $379: 50$ & $3: 1$ & $39.87 \mathrm{~b}^{\mathrm{z}}$ & 3.84 & 6.64 \\
& & & $7: 1$ & 0.21 & 3.84 & 6.64 \\
& & & $15: 1$ & $20.48 \mathrm{~b}$ & 3.84 & 6.64 \\
2011 & \multirow{2}{*}{6.88} & $91: 17$ & $3: 1$ & $4.46 \mathrm{a}$ & 3.84 & 6.64 \\
& & & $7: 1$ & 0.76 & 3.84 & 6.64 \\
$2010+2011$ & \multirow{2}{*}{5.77} & $435: 71$ & $15: 1$ & $15.02 \mathrm{~b}$ & 3.84 & 6.64 \\
& & & $3: 1$ & $31.39 \mathrm{~b}$ & 3.84 & 6.64 \\
& & & $7: 1$ & 1.02 & 3.84 & 6.64 \\
& & & $15: 1$ & $49.45 \mathrm{~b}$ & 3.84 & 6.64 \\
\hline
\end{tabular}

$\mathrm{z}_{\mathrm{a} P}<0.05 ; \mathrm{b} P<0.01$

Screening for microsatellite markers and major gene mapping. Of the 600 pairs of SSR and EST-SSR primers, 266 pairs of polymorphic primers were identified in the hybrid population. These polymorphic markers were well distributed on all of the 17 linkage groups with 10 to 27 on each. Any marker closely linked to light browning, i.e., the specific electrophoretic band amplified with the polymorphic primers, was expected to be absent in all seedlings with heavy-browning phenotype. The 100 seedlings with light-browning phenotype were randomly chosen; therefore, the recessive phenotype was excluded, and the 
Table 2. Heritability estimates of flesh browning in a hybrid population of 'Jonathan' $\times$ 'Golden Delicious'.

\begin{tabular}{|c|c|c|c|c|c|c|}
\hline $\mathrm{Yr}$ & $\begin{array}{c}\text { Population } \\
\text { variance }(\mathrm{S})\end{array}$ & $\begin{array}{c}\text { Major gene } \\
\text { variance }(\mathrm{Sa})\end{array}$ & $\begin{array}{c}\text { Polygene } \\
\text { variance }(\mathrm{Si})\end{array}$ & $\begin{array}{c}\text { Environmental } \\
\text { variance }(\mathrm{Se})\end{array}$ & $\begin{array}{l}\text { Heritability of major } \\
\text { gene effect }(\%)\end{array}$ & $\begin{array}{c}\text { Heritability of polygene } \\
\text { effect }(\%)\end{array}$ \\
\hline 2010 & 4.221 & 3.045 & 0.559 & 0.617 & 72.14 & 13.23 \\
\hline 2011 & 5.180 & 3.769 & 0.794 & 0.617 & 72.76 & 15.32 \\
\hline $2010+2011$ & 4.569 & 3.094 & 0.858 & 0.617 & 67.72 & 18.77 \\
\hline
\end{tabular}

Table 3. Microsatellite markers linked to the trait of light browning in hybrid population of 'Jonathan' $\times$ 'Golden Delicious'.

\begin{tabular}{|c|c|c|c|c|c|c|c|c|c|}
\hline Marker & $\begin{array}{l}\text { Size of the polymorphic } \\
\text { fragments (bp) }\end{array}$ & Jonathan & $\begin{array}{l}\text { Golden } \\
\text { Delicious }\end{array}$ & $\begin{array}{c}\text { Observed } \\
\text { segregation ratio }\end{array}$ & $\begin{array}{l}\text { Expected } \\
\text { ratio }\end{array}$ & $\chi^{2 z}$ & $\begin{array}{l}\text { Linkage } \\
\text { group }\end{array}$ & $\begin{array}{l}\text { Recombination } \\
\text { rate }(\%)\end{array}$ & $\begin{array}{c}\text { Map } \\
\text { distance }(\mathrm{cM})\end{array}$ \\
\hline Hi22f04 & 147 & + & - & $56: 44$ & $4: 3$ & 0.02 & 10 & 21.7 & 23.3 \\
\hline $\mathrm{CH} 02 \mathrm{a} 10$ & 216 & + & - & $63: 37$ & $4: 3$ & 1.17 & 10 & 19.6 & 20.7 \\
\hline $\mathrm{CH} 02 \mathrm{~b} 07$ & 188 & + & - & $53: 47$ & $4: 3$ & 0.54 & 10 & 23.9 & 26.0 \\
\hline CN911379 & 275 & + & - & $54: 46$ & $4: 3$ & 0.29 & 15 & 10.9 & 11.0 \\
\hline $\mathrm{CH} 03 \mathrm{~b} 01$ & 425 & + & - & $49: 51$ & $4: 3$ & 2.39 & 15 & 21.7 & 23.3 \\
\hline AJ001681-SSR & 187 & - & + & $55: 45$ & $4: 3$ & 0.11 & 17 & 10.9 & 11.0 \\
\hline AT000174-SSR & 186 & - & + & $48: 52$ & $4: 3$ & 3.05 & 17 & 10.9 & 11.0 \\
\hline $\mathrm{CH} 04 \mathrm{c} 06$ & 186 & - & + & $58: 42$ & $4: 3$ & 0.01 & 17 & 23.9 & 26.0 \\
\hline
\end{tabular}

${ }^{2} \chi_{0.05}^{2}=3.84$.

ratio of presence/absence of the specific bands should be $4: 3$ or $6: 1$ theoretically. In cases in which the marker was not absent in a few seedlings with heavy-browning phenotype, the marker-present seedlings were regarded as genetic recombinants.

Eight SSR markers (Hi22f04, CH02a10, CH02b07, CN911379, CH03b01, AJ001681SSR, AT000174-SSR, and CH04c06) of 266 pairs of primers were unambiguously identified as being linked to the light-browning trait (Table 3). The segregation ratio of all eight markers in the 100 seedlings with light-browning phenotype was 4:3. Markers Hi22f04, CH02a10, CH02b07, CN911379, and $\mathrm{CH} 03 \mathrm{~b} 01$ appeared in the maternal parent 'Jonathan', whereas AJ001681-SSR, AT000174-SSR, and CH04c06 appeared in the pollen parent 'Golden Delicious' (Table 3).

Markers Hi22f04, CH02a10, and CH02b07 were located on LG10 (Silfverberg-Dilworth et al., 2006). Their PCR amplification yielded three polymorphic fragments of $147 \mathrm{bp}, 216 \mathrm{bp}$, and $188 \mathrm{bp}$, respectively. Of the 46 seedlings (four seedlings were suspected as outbreeders and were excluded) with heavy-browning phenotype, 10, nine, and 11 seedlings appeared as recombinants and the recombination rate of the markers $\mathrm{Hi} 22 \mathrm{f0} 4, \mathrm{CH} 02 \mathrm{a} 10$, and $\mathrm{CH} 02 \mathrm{~b} 07$ was $21.7 \%, 19.6 \%$, and $23.9 \%$, respectively. Thus, the map distances between the light-browning major gene locus and markers Hi22f04, $\mathrm{CH} 02 \mathrm{a} 10$, and $\mathrm{CH} 02 \mathrm{~b} 07$ were estimated as $23.3,20.7$, and $26.0 \mathrm{cM}$, respectively. Based on the distance $(44 \mathrm{cM})$ between Hi22f04 and $\mathrm{CH} 02 \mathrm{a} 10$, also the distance $(15.8 \mathrm{cM})$ between $\mathrm{CH} 02 \mathrm{a} 10$ and $\mathrm{CH} 02 \mathrm{~b} 07$ on the linkage map of Discovery (Silfverberg-Dilworth et al., 2006), Hi22f04, and $\mathrm{CH} 02 \mathrm{a} 10$ putatively flanked the target gene $\mathrm{B}_{10}$ (B: dominant locus for the light browning; subscript number: linkage group) and $\mathrm{CHO2b07} \mathrm{located} \mathrm{at} \mathrm{the} \mathrm{same} \mathrm{side} \mathrm{with}$ CH02a10 (Fig. 2).

Both the markers CN911379 and CH03b01 were located on LG15 according to Zhang et al. (2012). CN911379 and CH03b01 generated specific fragments of $275 \mathrm{bp}$ and $425 \mathrm{bp}$, respectively. Five and 10 seedlings appeared as
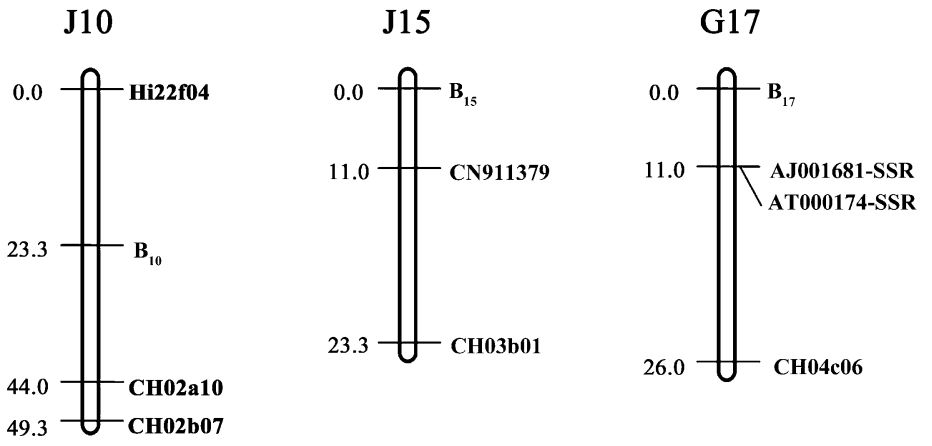

Fig. 2. Mapping of light browning-related major genes in a hybrid population of 'Jonathan' $\times$ 'Golden Delicious'. Numbers on the left of each linkage group (LG) indicate the map distance (cM). Bold letters on the right of each LG indicate major gene loci and associated markers of flesh browning. $\mathrm{J}=$ 'Jonathan'; $\mathrm{G}=$ 'Golden Delicious' and following number means the linkage group on apple genome.

recombinants in the 46 seedlings of the heavybrowning population, and the recombination rate was $10.9 \%$ and $21.7 \%$ for CN911379 and $\mathrm{CH} 03 \mathrm{~b} 01$, respectively. The map distances for the two markers CN911379 and CH03b01 were 11.0 and $23.3 \mathrm{cM}$, respectively. The distance between these two markers was calculated as $18.8 \mathrm{cM}$ using Mapmaker software. Thus, CN911379 and CH03b01 were postulated to be located at the same side of the target gene $\mathrm{B}_{15}$ (Fig. 2).

Markers AJ001681-SSR, AT000174-SSR, and $\mathrm{CH} 04 \mathrm{c} 06$ on $\mathrm{LG} 17$ yielded three specific fragments of $187 \mathrm{bp}, 186 \mathrm{bp}$, and $186 \mathrm{bp}$, respectively. Of the 46 seedlings of the heavybrowning population, five, five, and 11 recombinant seedlings contributed to $10.9 \%$, $10.9 \%$, and $23.9 \%$ of the recombination and the map distances between the light-browning major gene locus and markers AJ001681-SSR, AT000174-SSR, and $\mathrm{CH04c06}$ were estimated as $11.0,11.0$, and $26.0 \mathrm{cM}$, respectively. The map distance between AJ001681SSR and $\mathrm{CH04c06}$ was calculated $16.6 \mathrm{cM}$ using Mapmaker software, and the distance between AJ001681-SSR and AT000174-SSR was only $4.1 \mathrm{cM}$. Thus, AJ001681-SSR, AT000174-SSR, and CH04c06 were mapped on the same side of the target gene $\mathrm{B}_{17}$ (Fig. 2).

Summarizing the results of inheritance and major gene mapping for apple flesh browning in this hybrid population, the genotype of maternal parent, 'Jonathan', was presumed to be $B_{10} b_{10} B_{15} b_{15} b_{17} b_{17}$ and that of paternal parent, 'Golden Delicious', was $b_{10} b_{10} b_{15} b_{15} B_{17} b_{17}$ (B: dominant locus for the light browning; $b$ : recessive locus for the heavy browning; subscript number: linkage group).

Identification of $Q T L_{S}$ for flesh browning. By interval mapping model using the genomewide significant threshold LOD 2.8, no QTL was detected for flesh browning. However, using the LG-specific LOD threshold, two minor QTLs, qtl1 and qt12, were mapped on LG15 of 'Jonathan' and LG17 of 'Golden Delicious', respectively, using the fruit freshcut browning phenotyping data in 2010. The peak LOD value of qt11 was 1.75 , which was higher than the LG-specific LOD threshold value (1.7); qtll contributed with $11.6 \%$ of variance explanation. The peak of qtl1was associated with marker CN911379 (K=6.482 and $P<0.01)$ based on the Kruskal-Wallis analyses. Because there was a gap on the LG17 linkage map of 'Golden Delicious' (Zhang et al., 2012), qt12 was identified on the part that only has two SSR markers NZmsEB137525 and CN938125 with an LGspecific LOD threshold value of 1.1. The QTL was located in the 11-cM interval between these two markers supported with a high peak 
Table 4. Quantitative trait loci (QTLs) for fresh-cut browning detected by interval mapping and Kruskal-Wallis in 2010 in the hybrid population of 'Jonathan' $\times$ 'Golden Delicious'.

\begin{tabular}{|c|c|c|c|c|c|c|c|c|}
\hline \multirow[b]{2}{*}{ QTL } & \multirow[b]{2}{*}{ LG } & \multicolumn{3}{|c|}{ Interval mapping } & \multicolumn{4}{|c|}{ Kruskal-Wallis analysis } \\
\hline & & Peak Position (cM) & LOD/LG-specific LOD threshold & Variance explained (\%) & Marker & Position (cM) & $\mathrm{K}$ & Significance levels \\
\hline qt12 & G17 & 3.00 & $1.85 / 1.1$ & 14.0 & NZmsEB137525 & 0.00 & 7.880 & 0.001 \\
\hline
\end{tabular}

चJ15: linkage group 15 of 'Jonathan'; G17: linkage group 17 of 'Golden Delicious'

LOD $=$ likelihood of odd; $\mathrm{LG}=$ linkage group.

LOD value of 1.85 and explaining $14.0 \%$ phenotypic variation. According to the Kruskal-Wallis analysis, both NZmsEB137525 and CN938125 linked with qt12 $(\mathrm{K}=7.880$, 7.447 and $P<0.001,0.005$, respectively) (Table 4). As a result of alternate bearing between years, only 12 of the 242 mapping populations set fruit in 2011; no QTLs were identified successfully.

\section{Discussion}

Environmental effects have more influence on QTLs, or even major QTLs, but relatively less influence on the qualitative/quantitative traits involving major genes. Two major QTLs associating the rate of apple flesh browning were identified in a hybrid population of 'Telamon' $\times$ 'Braeburn' in 2005 (Kenis et al., 2008). However, the major QTLs were not stable from year to year, because neither of the two flesh browning-associated major QTLs were detected in 2004. In addition, only one of the 17 major QTLs for several fruit quality traits including fruit size and weight, flesh firmness, acidity and sugar content, and harvest date was year-stable (Kenis et al., 2008). Flesh browning is mostly caused by the oxidation of phenolic compounds. Both the content and antioxidant capacity of phenolic compounds are influenced by multiple factors such as maturity, temperature, and light (Gómez et al., 2010; Marta et al., 2011; Murata et al., 1995). This may explain the difference in QTLs for flesh browning previously reported by Kenis et al. (2008). Major gene segregation and polygenetic effects were detected in flesh browning in the present hybrid population, and the heritability of the major gene effect reached $72.14 \%$ and $72.76 \%$ in 2010 and 2011, respectively. These suggested that major genes contributed more to the variation in flesh browning in our hybrid population, and a good robustness of the segregation ratio of major genes was confirmed between years.

Besides quantitative loci, major genes can also be identified by QTL analysis (SouffletFreslon et al., 2008). In our case, two QTLs related to fruit fresh-cut browning were mapped using phenotyping data in 2010. Although we could not define them as major QTLs because the contribution to phenotypic variation was lower than $20 \%$ (Mellidou et al., 2012), the results of the QTL were perfectly coordinated with that of major gene mapping. qt11 and major gene B15 were both associated with marker CN911379. Both qt12 and major gene B17 were mapped on LG17 of 'Golden Delicious'.
PPO activity is controlled by polygenes in many plants such as wheat, tomatoes, and apples (Boss et al., 1995; Demeke and Morris, 2002; Newman et al., 1993). The major gene that controls wheat PPO activity has been identified on chromosome 2D (Tigst et al., 2001). In the hybrid population of 'Telamon' $x$ 'Braeburn', a normal distribution in the ascorbic acid content implied a quantitative genetic control of ascorbate in apple. Several QTLs associated with ascorbic acid content have been identified on LG6, 10, and 11 in the apple genome (Davey et al., 2006). The QTL identified by Davey and colleagues on LG10 (LOD 8.4) could explain $28.3 \%$ of total phenotypic variation, and the marker for this QTL, $\mathrm{CH} 03 \mathrm{~d} 11$, is only $11 \mathrm{cM}$ from our marker for the light browning-associated major gene, Hi22f04, according to the published map (Silfverberg-Dilworth et al., 2006). Oxidation of polyphenols and polyphenol concentrations were closely related to flesh browning (Amiot et al., 1992; Coseteng and Lee, 1987). In apple cultivar Braeburn, QTL for p-coumaroyl quinic acid in fruit cortex has been mapped on LG15, associated with single nucleotide polymorphism markers GDSNP01265 and GDSNP00932 (Chagne et al., 2012). The distance between the marker CN911379 for qt11 in our results and the two markers, GDSNP01265 and GDSNP00932, was not longer than $5 \mathrm{Mb}$ on the apple genome. A previous study indicated that one of the QTLs for the rate of flesh browning in the 'Telamon' $\times$ 'Braeburn' population is located on LG17 of 'Telamon'. This QTL accounts for $66.2 \%$ phenotypic variation and is a major QTL (Kenis et al., 2008). It may be related to the major gene locus $B_{17}$ in the present study.

Molecular marker-assisted breeding has been successfully used in apple, e.g., powdery mildew resistance and fireblight resistance (Evans and James, 2003; Khan et al., 2007). Marker-assisted inheritance analysis has been attempted for traits such as fruit shape index and ring rot susceptibility (Sun et al., 2012; Zhuang et al., 2011). In this study, we identified three major gene loci associated with flesh browning, which indicated that the trait of flesh browning is controlled by three major genes in this hybrid population. However, the map distances between the markers and the major gene loci in this report are all larger than $10 \mathrm{cM}$, and further study is required to reduce the map distance before their application in marker-assisted breeding practice.

In conclusion, the apple flesh browning is inherited quantitatively, and the inheritance involves three segregating loci of major genes. The three major genes were mapped on LG10,
15 , and 17 , but two minor QTLs were detected on the LG15 and LG17 on the apple genome, respectively, by using SSR markers.

\section{Literature Cited}

Amiot, M.J., M. Tacchini, S. Aubert, and J. Nicolas. 1992. Phenolic composition and browning susceptibility of various apple cultivars at maturity. J. Food Sci. 57:958-962.

Boss, P.K., R.C. Gardner, B.J. Janssen, and G.S Ross. 1995. An apple polyphenol oxidase cDNA is up-regulated in wounded tissues. Plant Mol. Biol. 27:429-433.

Buta, J.G., H.E. Moline, D.W. Spaulding, and C.Y. Wang. 1999. Extending storage life of fresh-cut apples using natural products and their derivatives. J. Agr. Food Chem. 47:1-6.

Chagne, D., C. Krieger, M. Rassam, M. Sullivan, J. Fraser, C. Andre, M. Pindo, M. Troggio, S.E. Gardiner, R.A. Henry, A.C. Allan, T.K. McGhie, and W.A. Laing. 2012. QTL and candidate gene mapping for polyphenolic composition in apple fruit. BMC Plant Biol. 12:12.

Choi, M.H., G.H. Kim, and H.S. Lee. 2002. Effects of ascorbic acid retention on juice color and pigment stability in blood orange (Citrus sinensis) juice during refrigerated storage. Food Res. Intl. 35:753-759.

Coseteng, M.Y. and C.Y. Lee. 1987. Changes in apple polyphenoloxidase and polyphenol concentrations in relation to degree of browning. J. Food Sci. 52:985-989.

Davey, M.W., K. Kenis, and J. Keulemans. 2006. Genetic control of fruit vitamin C content. Plant Physiol. 142:343-351.

Demeke, T. and C.F. Morris. 2002. Molecular characterization of wheat polyphenol oxidase (PPO). Theor. Appl. Genet. 104:813-818.

Dorantes-Alvarez, L., L. Parada-Dorantes, A. OrtizMoreno, T. Santiago-Pineda, A. Chiralt-Boix, and G. Barbosa-Cánovas. 1998. Effect of antibrowning compounds on the quality of minimally processed avocados. Food Sci. Technol. Intl. 4:107-113.

Evans, K.M. and C.M. James. 2003. Identification of SCAR markers linked to Pl-w mildew resistance in apple. Theor. Appl. Genet. 106:11781183.

Gianfranceschi, L., N. Seglias, R. Tarchini, M. Komjanc, and C. Gessler. 1998. Simple sequence repeats for the genetic analysis of apple. Theor. Appl. Genet. 96:1069-1076.

Gil, M.I., J.R. Gorny, and A.A. Kader. 1998. Responses of 'Fuji' apple slices to ascorbic acid treatments and low-oxygen atmospheres. HortScience 33:305-321.

Gómez, P.L., S.M. Alzamora, M.A. Castro, and D.M. Salvatori. 2010. Effect of ultraviolet-C light dose on quality of cut apple: Microorganism, color and compression behavior. J. Food Eng. 98:60-70.

Gorny, J.R., B. Hess-Pierce, R.A. Clifuentes, and A.A. Kader. 2002. Quality changes in fresh-cut pear slices as affected by controlled atmospheres and chemical preservatives. Postharvest Biol. Technol. 24:271-278. 
Guilford, P., S. Prakash, J.M. Zhu, E. Rikkerink, S. Gardiner, H. Bassett, and R. Forster. 1997. Microsatellites in Malus domestica (apple): Abundance, polymorphism and cultivar identification. Theor. Appl. Genet. 94:249-254.

Gunes, G., C.B. Watkins, and J.H. Hotchkiss. 2001. Physiological responses of fresh-cut apple slices under high $\mathrm{CO}_{2}$ and low $\mathrm{O}_{2}$ partial pressures. Postharvest Biol. Technol. 22:197-204.

Hokanson, S.C., A.K. Szewc-McFadden, W.F Lamboy, and J.R. McFerson. 1998. Microsatellite (SSR) markers reveal genetic identities, genetic diversity and relationships in a Malus domestica Borkh. core subset collection. Theor. Appl. Genet. 97:671-683.

Kenis, K., J. Keulemans, and M.W. Davey. 2008. Identification and stability of QTLs for fruit quality traits in apple. Tree Genet. Genomes 4:647-661.

Khan, M.A., C.E. Durel, B. Duffy, D. Drouet, M. Kellerhals, C. Gessler, and A. Patocchi. 2007. Development of molecular markers linked to the 'Fiesta' linkage group 7 major QTL for fire blight resistance and their application for markerassisted selection. Genome 50:568-577.

Kim, D.M., N.L. Smith, and C.Y. Lee. 1993. Quality of minimally processed apple slices from selected cultivars. J. Food Sci. 58:1115-1117.

Kumar, S., D. Chagne, M.C.A.M. Bink, R.K. Volz, C. Whitworth, and C. Carlisle. 2012. Genomic selection for fruit quality traits in apple (Malus domestica Borkh.). PLoS One 7:E36674.

Lamikanra, O. 2002. Enzymatic effects on flavor and texture of fresh-cut fruits and vegetables, p. 125-185. In: Lamikanra, O. (ed.). Fresh-cut fruits and vegetables: Science, technology and market. CRC Press, Boca Raton, FL.

Liebhard, R., L. Gianfranceschi, B. Koller, C.D. Ryder, R. Tarehim, E. Van De Weg, and C. Gessler. 2002. Development and characterization of 140 new microsatellites in apple (Malus domestica Borkh.). Mol. Breed. 10:217-241.

Liebhard, R., M. Kellerhals, W. Pfammatter, M. Jertmini, and C. Gessler. 2003. Mapping quantitative physiological traits in apple (Malus domestica Borkh.). Plant Mol. Biol. 52:511526.

Lincoln, S., M. Daly, and E. Lander. 1992. Construction genetic maps with MAPMAKER/EXP 3.0. Whitehead Institute Technical Report. 3rd Ed. Whitehead Institute, Cambridge, UK.
Liu, R.H. and J.L. Meng. 2003. MapDraw: A microsoft excel macro for drawing genetic linkage maps based on given genetic linkage data. Heraditas (Beijing) 25:317-321.

Luo, Y. and G.V. Barbosa-Cánovas. 1997. Enzymatic browning and its inhibition in new apple cultivars slices using 4-hexylresorcinol in combination with ascorbic acid. Food Sci. Technol. Intl. 3:195-201.

Maguire, T.L., G.G. Collins, and M. Sedgley. 1994 A modified CTAB DNA extraction procedure for plants belonging to the family Proteaceae. Plant Mol. Biol. Rpt. 12:106-109.

Marta, A., A. Carla, M.G. Elsa, P. Joaquina, M. Margarida, and E. José. 2011. Modeling of preheat treatment optimization applied to fresh-cut 'Rocha' pear. J. Food Qual. 34:315326.

Martínez, V.M. and J.R. Whitaker. 1995. The biochemistry and control of enzymatic browning. Trends Food Sci. Technol. 6:195-200.

Mellidou, I., D. Chagne, W.A. Laing, J. Keulemans, and M.W. Davey. 2012. Allelic variation in paralogs of GDP-1-galactose phosphorylase is a major determinant of vitamin $\mathrm{C}$ concentrations in apple fruit. Plant Physiol. 160:1613-1629.

Murata, M., M. Tsurutani, M. Tomita, S. Homma, and K. Kaneko. 1995. Relationship between apple ripening and browning: Changes in polyphenol content and polyphenol oxidase. J. Agr. Food Chem. 43:1115-1121.

Newman, S.M., N.T. Eannetta, H. Yu, J.P. Prince, M.C. Vicente, S.D. Tanksley, and J.C. Steffens. 1993. Organisation of the tomato polyphenol oxidase gene family. Plant Mol. Biol. 21:10351051.

Nicolas, J.J., F.C. Richard-Forget, P.M. Goupy, M.J. Amiot, and S. Aubert. 1994. Enzymatic browning reactions in apple and apple products. Crit. Rev. Food Sci. Nutr. 34:109-157.

Nie, L.C. and J.S. Sun. 2005. Study on the phenolic compound contents in apple of different cultivars. J. Chin. Inst. Food Sci. Technol. 5:118121[ in Chinese with English abstract].

Nie, L.C., J.S. Sun, B. Xin, and X.Q. Lu. 2004 Studies on phenolic composition and polyphenol oxidase activity in apple fruits. Acta Hort. Sinica. 31:502-504[ in Chinese with English abstract].

Silfverberg-Dilworth, E., C.L. Matasci, W.E. Van de Weg, M.P.W. Van Kaauwen, M. Walser, L.P.
Kodde, V. Soglio, L. Gianfranceschi, C.E. Durel, and F. Costa. 2006. Microsatellite markers spanning the apple (Malus domestica Borkh.) genome. Tree Genet. Genomes 2:202-224.

Song, Y., Y.X. Yao, H. Zhai, Y.P. Du, F. Chen, and S.W. Wei. 2007. Polyphenolic compound and the degree of browning in processing apple varieties. Agr. Sci. China 6:607-612.

Soufflet-Freslon, V., L. Gianfranceschi, A. Patocchi, and C.E. Durel. 2008. Inheritance studies of apple scab resistance and identification of Rvi14, a new major gene that acts together with other broad-spectrum QTL. Genome 51:657667.

Sun, H.H., Y.B. Zhao, C.M. Li, D.M. Chen, Y. Wang, X.Z. Zhang, and Z.H. Han. 2012. Identification of markers linked to major gene loci involved in determination of fruit shape index of apples (Malus domestica). Euphytica 185:185-193.

Tigst, D., F.M. Craig, G.C. Kimberly, E.K. Garrison, A.A. James, and C. Hak-Gil. 2001. Wheat polyphenol oxidase: Distribution and genetic mapping in three inbred line populations. Crop Sci. 41:1750-1757.

Van Ooijen, J.W., M.P. Boer, R.C. Jansen, and C. Maliepaard. 2009. MapQTL 6.0, Software for the calculation of QTL positions on genetic maps. Plant Research International, Wageningen, The Netherlands.

Wang, W., C.G. Chen, L. Zhang, and X. Zhao. 2004. Study on anti-brown treatments of MP lettuce. Food Sci. Technol. 3:32-34[ in Chinese with English abstract].

Xu, K.N., A.D. Wang, and S. Brown. 2012. Genetic characterization of the $M a$ locus with $\mathrm{pH}$ and titratable acidity in apple. Mol. Breed. 30:899912.

Zhang, Q., B.Q. Ma, H. Li, Y.S. Chang, Y.Y. Han, J. Li, G.C. Wei, S. Zhao, M.A. Khan, Y. Zhou, C. Gu, X.Z. Zhang, Z.H. Han, S.S. Korban, S.H. Li, and Y.P. Han. 2012. Identification, characterization, and utilization of genome-wide simple sequence repeats to identify a QTL for acidity in apple. BMC Genomics 13:537.

Zhuang, Y., H.T. Liu, C.M. Li, Y.B. Zhao, D.M. Chen, Z.H. Han, and X.Z. Zhang. 2011. Inheritance of and molecular markers for susceptibility of Malus domestica to fruit ring rot (Botryosphaeria dothidea). J. Phytopathol. 159: 782-788. 